\title{
On biaxiality of photoinduced structures in azopolymer films
}

\author{
A.Kiselev ${ }^{1}$, O. Yaroshchuk ${ }^{2}$, Yu.Zakrevskyy ${ }^{2}$, \\ A. Tereshchenko ${ }^{2}$ \\ 1 Chernigiv Technological University, \\ 95 Shevchenko Str., 14027 Chernigiv, Ukraine \\ 2 Institute of Physics of the National Academy of Sciences of Ukraine, \\ 46 Nauki Ave., 03028 Kyiv, Ukraine
}

Received August 1, 2000

\begin{abstract}
Spatial orientational structures in the layers of liquid crystalline polymalonates are investigated using UV absorption method and the results of the null ellipsometry technique. Preferential in-plane alignment of azobenzene fragments and in-plane reorientation under irradiation with polarized UV light are established. The components of the order parameter tensor of azobenzene fragments are estimated for the initial state and after different doses of irradiation. The uniaxial as well as biaxial order of the azobenzene chromophores are detected. The biaxiality is observed in the intermediate stages of irradiation, whereas the uniaxial order is realized in the saturated state. The proposed theory takes into account biaxiality of the induced structures and describes well the experimental dependencies of the order parameter components on the time of irradiation.
\end{abstract}

Key words: azopolymer, photo-induced anisotropy, spatial orientation

PACS: $61.30 . G d, 42.65 .-k, 78.66 . Q n$

\section{Introduction}

The photoinduced anisotropy (POA) in azopolymer films is a well-known phenomenon that is extremely promising for applications in systems for optical storage and computing, telecommunication, holography etc. [1]. Besides, photooriented polymer layers are excellent aligning substrates for liquid crystals [2]. The microscopic origin of POA in azopolymers is assumed to be a photoinduced orientational ordering of azobenzene moieties in the direction perpendicular to polarization direction of the exciting light E. Mechanisms of such orientational ordering are described elsewhere [1,3]. As far as the spatial case is concerned, there are many directions perpendicular to E. The variety of orientational 3D structures (uniaxial, biaxial, splayed with different spatial orientation of the principal axes) can be observed de- 
pending on many factors such as chemical structure, method of film preparation, irradiation conditions and so on. The study of the 3D orientational structures in polymer films was restrained with the lack of effective experimental methods. The known approaches $[4,5]$ are associated with a limited field of application and strong approximations. For the sake of simplicity, in the experimental studies $[1,6,7]$ and even in theoretical calculations [3] uniaxial ordering had been assumed. The first attempt to estimate the biaxiality was by Wiesner et al. [5] that used the results of IR (infrared) absorption. The weak point of the approach [5] is that it can be applied only to the special orientational configuration and requires to known the original orientational structure. We used this method to process the data of UV (ultraviolet) absorption. On the other hand, the method of null ellipsometry is complementary to the UV spectroscopic measurements. By using it we estimated $[8,9]$ the type of the 3D orientational configuration before irradiation as well as after subsequent periods of irradiation. These results combined with the UV absorption measurements allowed us to estimate the components of the order parameter tensor of azobenzene chromophores. Our theoretical approach to the photoinduced ordering in azopolymers is based on kinetic rate equations extended to take into consideration the biaxiality of the induced structures. As a result, we computed the order parameter components of azobenzene units for different irradiation doses. The predictions of the theory are in good agreement with the data obtained experimentally.

\section{Experimental}

\subsection{Samples}

We used the poly[octyl(4-hexyloxy-4'-nitro)azobenzenemalonate] which synthesis is described in [10]. The polymer was solved in dichloroethane and spincoated on the quartz slabs. The prepared films were kept at room temperature for $24 \mathrm{~h}$ for the solvent to evaporate.

To induce anisotropy in the films, we used irradiation by a $\mathrm{Hg}$ lamp. The intensity of the actinic light was about $4.0 \mathrm{~mW}$. A Glan-Thomson polarizer was applied for the polarization of UV light. We used normal incidence of the actinic light in our studies. The irradiation was provided in several steps followed by absorption measurements.

\subsection{Method}

The UV/Vis (ultraviolet/visible) absorption measurements were carried out using a PC conjugated spectrometer KSVU (LOMO, Russia). The wavelength of the testing light was tuned to the absorption maximum of the azobenzene fragments. The testing beam was polarized and directed normally to the film plane. Absorption components in the direction of the exciting light polarization $\mathbf{E}$ and perpendicularly

to $\mathbf{E}$ were measured. We denote them as $D_{x}$ and $D_{y}$, respectively. The out-of-plane absorption component, $D_{z}$, was estimated by making use of the method proposed in [5]. The latter assumes that the sample has uniaxial structure with in-plane position of the axis of anisotropy at the instant of time $t_{0}$. It implies that $D_{z}\left(t_{0}\right)=D_{x}\left(t_{0}\right)$ 
and the total (spatial) absorption can be estimated as follows

$$
D_{\text {total }}=D_{x}\left(t_{0}\right)+D_{y}\left(t_{0}\right)+D_{z}\left(t_{0}\right)=2 D_{x}\left(t_{0}\right)+D_{y}\left(t_{0}\right) .
$$

When the number of trans azobenzene units does not change considerably, the total absorption is constant and the value of $D_{z}$ at the instant of time $t$ can be determined from the following equation:

$$
D_{z}(t)=D_{\text {total }}-D_{x}(t)-D_{y}(t)
$$

where $D_{x}(t)$ and $D_{y}(t)$ are experimentally measured parameters.

\subsection{Results and discussion}

The UV/Vis spectra of the studied compound have an intensive absorption band with the maximum at $\lambda_{\mathrm{t}}=377 \mathrm{~nm}$ corresponding to the $\pi \pi^{*}$ transition of trans azobenzene fragments. The wavelength of the testing beam was tuned to this value. After switching off the actinic light, the spectrum revealed changes that became stationary for approximately $5 \mathrm{~min}$. In order to have the azobenzene units relaxed to the stationary state, the components $D_{x}$ and $D_{y}$ were measured 15 min after each irradiation period.

In order to estimate a lifetime of cis isomers, we have measured the relaxation of the spectral changes at $\lambda_{\mathrm{t}}=377 \mathrm{~nm}$ after irradiation with non-polarized light. The incidence directions of both actinic and testing light were approximately normal to the film. It was found that the relaxation curve contains two components with characteristic times of $0.5 \mathrm{~s}$ and $4 \mathrm{~min}$, respectively. The first value can be attributed to cis-trans transition of azobenzene chromophores, whereas the second one corresponds to orientational relaxation of the units.

The experimentally measured absorption components $D_{x}$ and $D_{y}$ for different irradiation doses are presented in figure 1a. The kinetics of $D_{x}$ and $D_{y}$ is typical for the reorientation mechanisms of azobenzene units [3]. Both curves $D_{x}(t)$ and $D_{y}(t)$ reveal saturation. As it was shown earlier shown by null ellipsometry method $[8,9]$, the saturated state of the film of the studied polymer is fitted as uniaxial structure with the in-plane orientation of the axis of anisotropy. Taking it into account and additionally assuming that lifetime of cis form is about $0.5 \mathrm{~s}$ we arrive at the conclusion that, in our experimental case, the method described above can be applied to estimate $D_{z}$. The values of $D_{z}$ calculated by means of equations (1)-(2) are also presented in figure 1a. Dependencies $D_{x}(t), D_{y}(t)$ and $D_{x}(t)$ show that the photoinduced ordering is mainly due to the in-plane reorientation of azobenzene fragments in the $y$ direction. In addition, slight reorientation from $x$ to $z$ direction is observed.

The orientational structure in general case is described by the tensor $S_{i j}$, which is diagonal when the coordinate axes directed along the principal axes of the film. The diagonal elements $S_{x x} \equiv S_{x}, S_{y y} \equiv S_{y}$ and $S_{z z} \equiv S_{x}$ are related to the absorption components $D_{x}, D_{y}$ and $D_{z}[5]$. For example,

$$
S_{x}=\frac{2 D_{x}-\left(D_{y}+D_{z}\right)}{2\left(D_{x}+D_{y}+D_{z}\right)}
$$



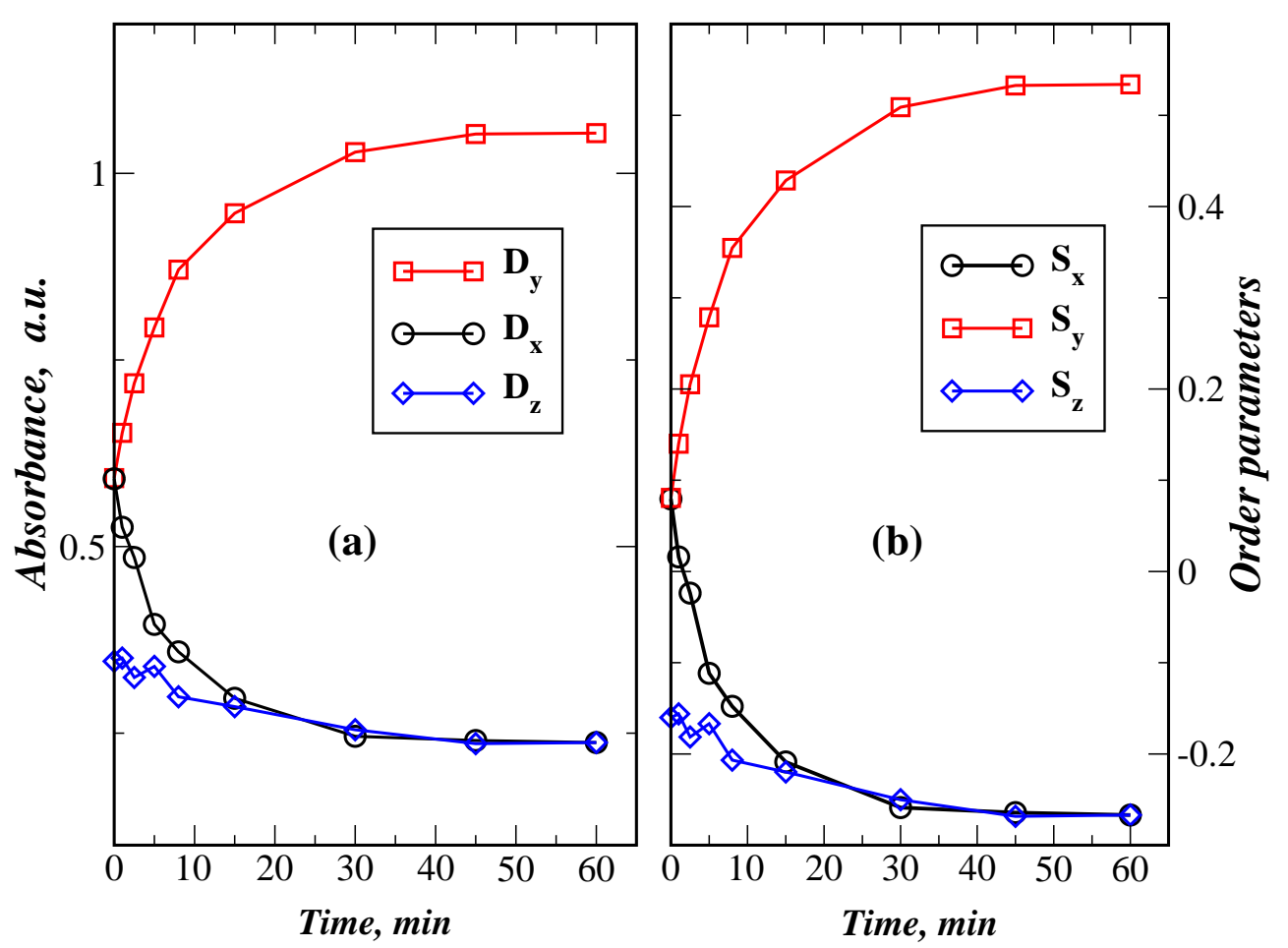

Figure 1. Dependencies of (a) the principle absorption coefficients and (b) components of the order parameter on irradiation time.

The components $S_{y}$ and $S_{z}$ can be obtained by cyclic permutation in the expression (3). The values of $S_{x}, S_{y}$ and $S_{z}$ calculated using equation (3) are presented in figure $1 \mathrm{~b}$. It is seen that the initial stage of irradiation is characterized by biaxiality, whereas the photosaturated stage by is characterized uniaxial orientation with the order parameter about 0.7. According to [9], the uniaxiality of the saturated state could be caused by mesomorphic properties of azobenzene fragments. The action of actinic light then can be considered as a factor stimulating the selforganization peculiar to mesophases [11]. From this point of view, the realized structure is a result of photoreorientation and selfassembling processes in the film.

\section{Theory}

In this section we briefly discuss our theoretical approach to the kinetics of the photoinduced reorientation. Starting from the master equations, we then specify the rates of the transitions involved. The final kinetic equations for the order parameters are derived after making assumptions regarding the form of the angular redistribution probabilities. In addition, this phenomenological model includes a set of order parameters that characterizes main chain orientation of the polymer. 


\subsection{Master equations}

In what follows we shall assume that the dye molecules in the ground state are of the trans form with the orientation of the molecular axis defined by the unit vector $\hat{\mathbf{n}}$. The latter is specified by the polar, $\theta$, and azimuthal, $\phi$, angles: $\hat{\mathbf{n}}=(\sin \theta \cos \phi, \sin \theta \sin \phi, \cos \theta)$.

Angular distribution of the trans molecules is characterized by the distribution function $F_{\operatorname{tr}}(\hat{\mathbf{n}})$. Molecules in the excited state have the cis conformation and the corresponding distribution function is $F_{\text {cis }}(\hat{\mathbf{n}})$. Then for the number of trans and cis molecules we have

$$
N_{\mathrm{tr}}=\int F_{\mathrm{tr}}(\hat{\mathbf{n}}) \mathrm{d} \hat{\mathbf{n}}, \quad N_{\text {cis }}=\int F_{\text {cis }}(\hat{\mathbf{n}}) \mathrm{d} \hat{\mathbf{n}}, \quad N=N_{\text {tr }}+N_{\text {cis }},
$$

respectively, and $N$ is the total number of molecules.

Introducing the normalized distribution functions $f_{1}(\hat{\mathbf{n}}) \equiv F_{\mathrm{tr}} / N$ and $f_{2}(\hat{\mathbf{n}}) \equiv$ $F_{\text {cis }} / N$, we write the kinetic rate equations of the following general form $[12,13]$ :

$$
\frac{\partial f_{i}}{\partial t}=\left[\frac{\mathrm{d} f_{i}}{\mathrm{~d} t}\right]_{\operatorname{Diff}}+\sum_{j=1}^{2} \int\left[W_{i j}\left(\hat{\mathbf{n}}, \hat{\mathbf{n}}^{\prime}\right) f_{j}\left(\hat{\mathbf{n}}^{\prime}, t\right)-W_{j i}\left(\hat{\mathbf{n}}^{\prime}, \hat{\mathbf{n}}\right) f_{i}(\hat{\mathbf{n}}, t),\right] \mathrm{d} \hat{\mathbf{n}}^{\prime}
$$

where $i=1,2$. The first term on the right hand side of equation (5) is due to rotational diffusion of molecules in trans $(i=1)$ and cis $(i=2)$ conformations, so that the terms proportional to $W_{i i}$ can be incorporated into the diffusion term. The remaining part of equation (5) accounts for trans-cis (terms proportional to $W_{21}$ ) and cis-trans (terms proportional to $W_{12}$ ) transitions.

The trans-cis transition is stimulated by the incident UV-light quasiresonant to the corresponding transition. Assuming that the electromagnetic wave is linearly polarized along the $x$-axis, the rate of the transition can be written as follows $[3,14]$ :

$$
\begin{gathered}
W_{21}\left(\hat{\mathbf{n}}, \hat{\mathbf{n}}^{\prime}\right)=\Gamma_{\operatorname{tr}}\left(\hat{\mathbf{n}}, \hat{\mathbf{n}}^{\prime}\right) P_{\operatorname{tr}}\left(\hat{\mathbf{n}}^{\prime}\right), \\
P_{\mathrm{tr}}\left(\hat{\mathbf{n}}^{\prime}\right)=\Phi_{\operatorname{tr} \rightarrow \operatorname{cis}} \sum_{i, j} \sigma_{i j}^{(\operatorname{tr})}\left(\hat{\mathbf{n}}^{\prime}\right) E_{i} E_{j}^{*}=q_{\mathrm{t}} I\left(1+u n_{x}^{2}\right),
\end{gathered}
$$

where $\boldsymbol{\sigma}^{(\mathrm{tr})}(\hat{\mathbf{n}})$ is the tensor of absorption cross section for a trans molecule oriented along $\hat{\mathbf{n}}: \sigma_{i j}^{(\operatorname{tr})}=\sigma_{\perp}^{(\operatorname{tr})} \delta_{i j}+\left(\sigma_{\|}^{(\operatorname{tr})}-\sigma_{\perp}^{(\operatorname{tr})}\right) n_{i} n_{j}, u \equiv\left(\sigma_{\|}^{(\operatorname{tr})}-\sigma_{\perp}^{(\operatorname{tr})}\right) / \sigma_{\perp}^{(\operatorname{tr})}$ and $\Phi_{\text {tr } \rightarrow \text { cis }}$ is the quantum yield of the process; $\Gamma_{\operatorname{tr}}\left(\hat{\mathbf{n}}, \hat{\mathbf{n}}^{\prime}\right)$ describes the angular redistribution of molecules excited in the cis state; $I$ is the pumping intensity.

For the cis-trans transition along the same line of arguments we have

$$
W_{12}\left(\hat{\mathbf{n}}, \hat{\mathbf{n}}^{\prime}\right)=\left(\gamma_{\mathrm{c}}+q_{\mathrm{c}} I\right) \Gamma_{\mathrm{c}}\left(\hat{\mathbf{n}}, \hat{\mathbf{n}}^{\prime}\right), \quad q_{\mathrm{c}} \equiv \Phi_{\text {cis } \rightarrow \operatorname{trans}} \sigma^{(\mathrm{cis})}
$$

where $\gamma_{\mathrm{c}} \equiv 1 / \tau_{\mathrm{c}}, \tau_{\mathrm{c}}$ is the lifetime of cis molecule and the anisotropic part of absorption cross section is disregarded, $\sigma_{\|}^{\text {(cis) }}=\sigma_{\perp}^{\text {(cis) }} \equiv \sigma^{\text {(cis) }}$. 


\subsection{Order parameters}

The following three order parameters are of our primary concern:

$$
\begin{aligned}
& S_{x}=\left\langle 3 n_{x}^{2}-1\right\rangle / 2 \equiv-S_{0} / 2+\sqrt{3 / 2} S_{2}, \\
& S_{y}=\left\langle 3 n_{y}^{2}-1\right\rangle / 2 \equiv-S_{0} / 2-\sqrt{3 / 2} S_{2}, \\
& S_{z}=\left\langle 3 n_{z}^{2}-1\right\rangle / 2 \equiv S_{0}
\end{aligned}
$$

where $\langle\Psi\rangle \equiv \int \Psi f_{1} \mathrm{~d} \hat{\mathbf{n}}$.

We can now expand the distribution functions $f_{i}(\hat{\mathbf{n}})$ in spherical functions and derive equations for the corresponding components. The next step involves truncating the system and computing the kernels of angular redistribution. Omitting the details, in the simplest case, we have the following system of kinetic equations:

$$
\begin{aligned}
\frac{\partial n}{\partial t}= & -\left(\gamma_{\mathrm{c}}+q_{\mathrm{c}} I\right) n+\bar{q}_{\mathrm{t}} I\left(1-n+\bar{u} S_{x}\right), \\
\frac{\partial S_{i}}{\partial t}= & -\bar{q}_{\mathrm{t}} I\left[\sum_{j=0,2} w_{i j} S_{j}-v(1-n)\left(\delta_{i, 0}-\sqrt{3 / 8} \delta_{i, 2}\right)\right] \\
& -\left(\bar{q}_{\mathrm{t}} I+D_{\mathrm{t}}\right)\left(S_{i}-S_{i}^{(p)}\right)+\left(\gamma_{\mathrm{c}}+q_{\mathrm{c}} I\right) \Gamma_{\mathrm{c}} C_{i}, \\
\frac{\partial C_{i}}{\partial t}= & -\left(\gamma_{\mathrm{c}}+q_{\mathrm{c}} I+D_{\mathrm{c}}\right) C_{i}, \\
\frac{\partial S_{i}^{(p)}}{\partial t}= & \gamma_{p}\left(S_{i}-S_{i}^{(p)}\right), \quad i=0,2,
\end{aligned}
$$

where $n \equiv N_{\text {cis }} / N, \bar{q}_{\mathrm{t}} \equiv q_{\mathrm{t}}(1+u / 3), \bar{u} \equiv 2 u /(3+u), v \equiv \bar{u}[10 \pi]^{-1 / 2}, w_{22}=-w_{00}=$ $\bar{u} / 7, w_{02}=-2 w_{20}=\sqrt{6} w_{00} ; D_{\mathrm{c}} \equiv 6 D_{\mathrm{r}}^{(\mathrm{cis})}$ and $D_{\mathrm{t}} \equiv 6 D_{\mathrm{r}}^{(\mathrm{tr})}$ are rotational diffusion constants of cis and trans molecules, respectively. Additional order parameters $C_{i}$ and $S_{i}^{(p)}$ characterize ordering of intermediate states of cis molecules and ordering of polymer backbone [15], respectively.

\subsection{Steady state}

Equations (10) yield the uniaxial stationary state with

$$
S_{x}^{(\mathrm{st})}=S_{z}^{(\mathrm{st})}=S_{0}^{(\mathrm{st})} \Longleftrightarrow S_{2}^{(\mathrm{st})}=\sqrt{3 / 2} S_{0}^{(\mathrm{st})} .
$$

The result is

$$
S_{0}^{(\mathrm{st})}=\frac{\alpha v}{w_{00}+\sqrt{3 / 2} w_{02}+\beta v}, \quad 1-n_{\mathrm{st}}=\alpha-\beta S_{0}^{(\mathrm{st})},
$$

where

$$
\alpha=\frac{\gamma_{\mathrm{c}}+q_{\mathrm{c}} I}{\gamma_{\mathrm{c}}+\left(q_{\mathrm{c}}+\bar{q}_{\mathrm{t}}\right) I}, \quad \beta=\frac{\bar{u} \bar{q}_{\mathrm{t}} I}{\gamma_{\mathrm{c}}+\left(q_{\mathrm{c}}+\bar{q}_{\mathrm{t}}\right) I} .
$$




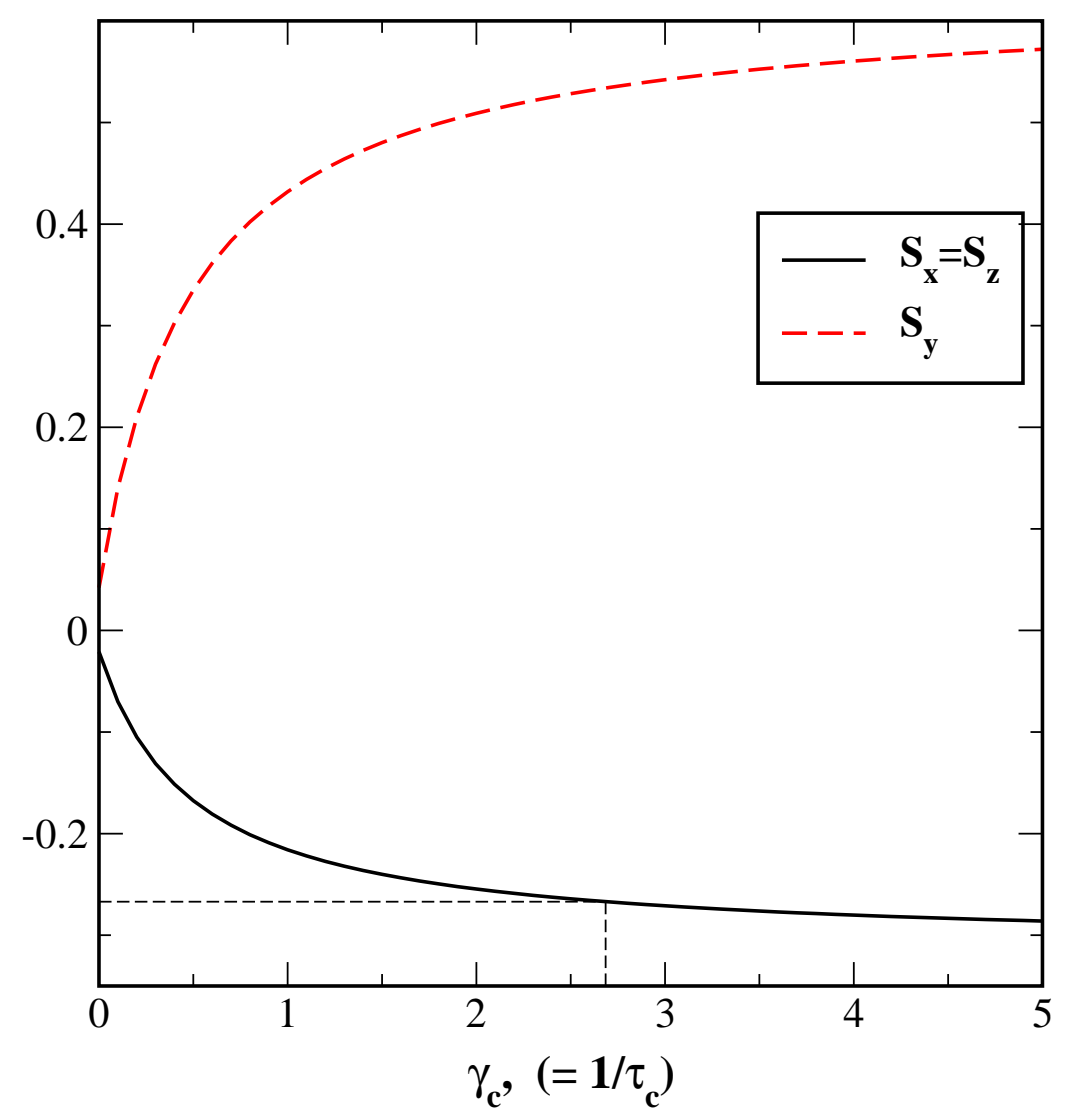

Figure 2. Stationary value of $S_{z}$ vs $\gamma_{\mathrm{c}} \equiv 1 / \tau_{\mathrm{c}}$ computed from equation (11). The lifetime of cis molecules is scaled by $\bar{q}_{\mathrm{t}} I$. The marked point corresponds to the experimental steady state value of $S_{z}, S_{z}^{(\text {st) }} \approx-0.267$.

According to figure $1 \mathrm{~b}$, experimental data give $S_{z}^{(\mathrm{st})}=S_{y}^{(\mathrm{st})} \approx-0.267$. Assuming that $u=19, \sigma^{(\mathrm{cis})} \approx \sigma_{\perp}^{(\mathrm{tr})}$, and $q_{\mathrm{t}} / q_{\mathrm{c}} \approx 30$ (see [15]), as it is shown in figure 2 , the relevant steady state order parameters can be calculated from equation (11).

Referring to figure 2 , it is seen that the experimental value of $S_{z}$ corresponds to $\gamma_{\mathrm{c}} \approx 2.68 \bar{q}_{\mathrm{t}} I$. From equation (11) we can now calculate $n_{\mathrm{st}}: n_{\mathrm{st}} \approx 0.14$. According to $[3,14]$, the mechanism of reorientation in our case, where the fraction of cis molecules in the photosteady state is found to be relatively small, corresponds to angular redistribution.

\section{Conclusions}

We have demonstrated that the UV absorption method supplemented by the null ellipsometry technique is an effective tool for the investigation of the features of spatial ordering in azopolymer films. This method is shown to detect spatial rearrangement of chromophores under irradiation. In addition, it enables us to calculate the components of the order parameter tensor for the original structures of the films as well as for structures at various stages of irradiation. 
Our theoretical approach to the kinetics of photoinduced reorientation is based on master equations with allowance for biaxiality. Predictions of the simple phenomenological model proposed in this paper are in good agreement with experimental data as far as the kinetics of order parameters and the photosteady state are concerned.

Although, for brevity, the details of the underlying theoretical considerations have been almost completely left aside in this paper, it should be emphasized that angular redistribution is of crucial importance in our approach. Moreover, in order to account for long term stability of the photoinduced isomerization, a more sophisticated treatment would involve the development of an effective medium theory. We plan to publish a more comprehensive discussion of this theory elsewhere.

\section{Acknowledgment}

We gratefully acknowledge financial support from U.S. Civilian Research \& Development Foundation (grant UP1-2121B).

\section{References}

1. Eich M., Wendorff H., Reck B., Ringsdorf H. // Macromol. Chem., Rapid Commun., 1987, vol. 8, p. 59 .

2. Gibbons W.M., Shannon P.J., Sun S.-T., Swetlin B.J. // Nature, 1991, vol. 351, p. 49.

3. Dumont M., Sekkat Z.// SPIE, 1992, vol. 1774, p. 188.

4. Blinov L.M., Dubinin N.V., Rumyancev V.G., Yudin S.G. // Sov. Optika i spectroskopiya, 1983, vol. 55, No. 4, p. 679 (in Russian).

5. Wiesner U., Reynolds N., Boeffel Ch., Spiess H.W. // Liq. Cryst., 1992, vol. 11, No. 2, p. 251.

6. Kulinna C., Hvilsted S., Hendann C., Siesler H., Ramanujam P.S. // Macromolecules, 1998, vol. 31, p. 2141.

7. Natansohn A., Rochon P., Meng X., Barett C., Buffeteau T., Bonenfant S., Pezolet M. // Macromolecules, 1998, vol. 31, p. 1155.

8. Chien L.-C., Kelly J., Lindau J., Sergan T., Yaroshchuk O. - In: Abstracts of OLC'99, Puerto Rico (USA), 26 September - 1 October 1999, p. 42.

9. Yaroshchuk O., Sergan T., Lindau J., Lee S.N., Kelly J., Chien L.-C. // Mol. Cryst. Liq. Cryst., 2000 (in press).

10. Böhme A., Novotna E., Kresse H., Kuschel F., Lindau J. // Macromol. Chem., 1993, vol. 194, p. 3341.

11. Fisher Th., Läsker L., Czapla S., Stumpe J. // Mol. Cryst. Liq. Cryst., 1997, vol. 299, p. 299.

12. van Kampen N.G. Stochastic Processes in Physics and Chemistry. Amsterdam, North - Holland Physics Publishing, 1984.

13. Gardiner C.W. Handbook of Stochastic Methods. Berlin, Springer - Verlag, 1985.

14. Dumont M. - In: Photoactive Organic Materials, eds. Kajzar et al., Netherlands, Kluwer Academic Publishers, 1996, p. 501.

15. Puchkovskaya G.A., Reshetnyak V.Yu., Tereshchenko A.G., Yaroshchuk O.V., Lindau J. // Mol. Cryst. Liq. Cryst., 1998, vol. 321, p. 31. 


\title{
Про двовісність фотоіндукованих структур в азополімерних плівках
}

\author{
О.Кисельов ${ }^{1}$, О.Ярощук ${ }^{2}$, Ю.Закревський ${ }^{2}$, \\ О.Терещенко ${ }^{2}$ \\ 1 Чернігівський технологічний університет, \\ 14027 Чернігів, вул. Шевченка, 95 \\ 2 Інститут фізики НАН України, 03028 Київ, пр. Науки, 46
}

Отримано 1 серпня 2000 р.

Шляхом використання методу УФ поглинання та результатів еліпсометричних вимірювань вивчені просторові орієнтаційні структури в шарах рідкокристалічних полімерів. Встановлено, що під дією поляризованого УФ випромінювання азобензольні фрагменти орієнтуються переважно в площині. Отримано оцінку для компонентів тензора параметра порядку як у початковому стані, так і після різних доз опромінювання. Виявлено як одновісне так і двовісне впорядкування азобензольних хромофорних груп. Причому двовісність спостерігається у проміжній стадії опромінювання, тоді як одновісний стан реалізується в режимі насичення. Запропонована теорія враховує двовісність індукованих структур і добре описує експериментальні залежності компонентів параметра порядку від часу опромінювання.

Ключові слова: азополімер, фотоіндукована анізотропія, просторова орієнтація

PACS: $61.30 . G d, 42.65 .-k, 78.66 . Q n$ 
